\section{BMJ Paediatrics Open}

\title{
Childhood injuries in Oman: retrospective review of a multicentre trauma registry data
}

Amber Mehmood, ${ }^{1}$ Priyanka Agrawal, ${ }^{1}$ Katharine A Allen, ${ }^{1}$ Ammar Al-Kashmiri, ${ }^{2}$ Ali Al-Busaidi, ${ }^{3}$ Adnan Ali Hyder ${ }^{1,4}$

To cite: Mehmood A, Agrawal P, Allen KA, et al. Childhood injuries in Oman: retrospective review of a multicentre trauma registry data. BMJ Paediatrics Open 2018;2:e000310. doi:10.1136/ bmjpo-2018-000310

- Additional material is published online only. To view please visit the journal online (http://dx.doi.org/10.1136/ bmjpo-2018-000310).

Received 11 May 2018 Revised 28 August 2018 Accepted 11 September 2018

Check for updates

(C) Author(s) (or their employer(s)) 2018. Re-use permitted under CC BY-NC. No commercial re-use. See rights and permissions. Published by BMJ.

${ }^{1}$ Johns Hopkins International Injury Research Unit, Department of International Health, Johns Hopkins Bloomberg School of Public Health, Baltimore, Maryland, USA

${ }^{2}$ Ministry of Health, Khoula Hospital, Mina Al Fahal, Oman ${ }^{3}$ Ministry of Health, Nizwa Hospital, Nizwa, Oman ${ }^{4}$ Department of Global Health, George Washington University Milken Institute School of Public Health, Washington, District of Columbia, USA

Correspondence to Dr Amber Mehmood; amehm002@jhu.edu

\section{ABSTRACT}

Objectives Injuries are among the top causes of hospital-based mortality for adults in Oman. However, little is known about the distribution and risk of injuries among children. This paper describes the epidemiology and risk factors for childhood injuries (0-15 years of age), in two hospitals of Oman.

Methods Data were collected between November 2014 and April 2015 at Khoula and Nizwa Hospitals. All patients between 0 and 15 years with a diagnosis of injury/trauma admitted to the hospital, and those who had trauma team activation in the emergency department were included in the analysis. Descriptive and multivariable Poisson regression analyses were conducted to generate sociodemographic risk factor profiles associated with the need for surgical management of injuries.

Results Out of 795 cases, $59 \%$ were under 5 years of age; $67 \%$ were males. Around $50 \%$ injuries were fall related, followed by exposure to inanimate mechanical forces and transport injuries. Burn injuries were more prevalent in females than males. Three-fourths of all injuries occurred in private residences. Almost $92 \%$ injuries were minor (Injury Severity Score <9). Of children with all types of injuries, $303(40.9 \%)$ received surgical treatment. Patients suffering from head injuries (RR 8.8: $95 \% \mathrm{Cl} 4.9$ to 15.3 ) or being involved in a burn injury (RR $1.5: 95 \% \mathrm{Cl}$ 0.3 to 7.5 ) were at increased risk of undergoing surgical treatment.

Conclusion In this study, $>30 \%$ of injury admissions were children $0-15$ years of age. The high incidence of falls, home injuries and burns highlight the need for agetargeted interventions and injury control programmes. Although infrequent, transport injuries and head injuries put children in need of surgical management and prolonged hospital care.

\section{INTRODUCTION}

Globally, around 5 million deaths reported in 2015 were due to injuries, contributing to almost $9 \%$ of all deaths and more than $10 \%$ of all disability-adjusted life years (DALY) lost. ${ }^{1}$ Unintentional injuries such as drowning, road traffic injuries (RTIs), falls and burns are the leading causes of injury deaths among those aged $0-15$ years. $^{2}{ }^{3}$ More than $90 \%$ of child injury deaths occur in low-income and

\section{What is already known on this topic?}

- Injuries are the leading cause of hospital-based mortality in individuals 1-44 years of age in the Sultanate of Oman.

- There is a knowledge gap in epidemiology and risk factor profile of injuries among children in the same population.

\section{What this study hopes to add?}

Among all hospital admissions due to an injury, 30\% were children under 15 years of age; falls, mechanical forces and road traffic accidents were leading causes of injury.

- Hospital-based trauma registries can be useful in providing a constant surveillance of the injury burden across all population demographics.

- Trauma Registriess (TRs) are a useful resource in risk-adjusted comparison of resource utilisation and outcome of paediatric patients admitted with injuries.

middle-income countries (LMICs) with injury death rates being 3-4 times higher in LMICs than in high-income countries (HICs). ${ }^{4}$

Rapidly developing HICs such as those in the Gulf Cooperation Council (GCC) have also observed a significant rise in the injury burden in recent years. ${ }^{4-6}$ Urbanisation, increased motorisation, migration for job opportunities and lack of integrated trauma systems are cited as some of the reasons for this ascending trend. ${ }^{78}$ While other LMICs in the Middle Eastern region are still focusing on maternal and child health, and communicable diseases, these rich gulf countries have made substantial gains in infant and child mortality only to be offset by the burden of injuries and non-communicable diseases. ${ }^{9-12}$ More than $20 \%$ of all deaths in the GCC were attributed to injuries and account for approximately $15 \%$ of all DALYs lost. ${ }^{13}$ 
The Sultanate of Oman, one of the six countries comprising the GCC, is located in the Southeast coast of the Arabian Peninsula. Almost 50\% of the population lives in the urban areas, that is, parts of Muscat and the Batinah coastal plain. Oman is a HIC with a total population of 4.8 million, where $13.9 \%$ and $33.7 \%$ of the population are under 5 years and under- 15 years, respectively. ${ }^{1415}$ In this country of mostly young individuals, injuries are the leading cause of hospital-based mortality in individuals 1-44 years of age. ${ }^{1}$ Despite an overall decrease in mortality from unintentional injuries by $38.9 \%$ since 1990, there has been a 50\% increase reported in RTIs for the same time frame, mainly affecting individuals 26-50 years of age ${ }^{16}$ With relatively under developed emergency medical services (EMSs) in rural areas and only a handful of dedicated trauma centres, many injury victims use private transport and receive initial assessment and care in smaller hospitals, before being transferred to urban trauma centres for definitive care. ${ }^{16}$ Additionally, trauma information systems are not widely implemented, and therefore, scarce information is available about the distribution and risk of injuries among children in Oman to make informed decisions about targeted age-specific policies and programmes on child injury prevention. ${ }^{17}$

In this paper, we analysed data from the trauma registry implemented in two Omani hospitals to describe the epidemiology and risk factors for injuries among children, who are defined as 15 years and below in the Omani hospital settings. This paper aims to provide a profile of paediatric injuries including the nature and intent of injuries across age and gender profiles, to better understand this burden in Oman and other GCC countries. It also demonstrates the value of collecting systematic data in hospital settings to inform injury prevention efforts. To our knowledge, this is the first such registry analysis from Oman in this population subset.

\section{METHODS}

In order to obtain a profile of injuries in Oman, a mHealth-based trauma registry was developed and pilot tested at two regional hospitals. ${ }^{18}$ Data were collected on patient characteristics and sociodemographic details such as age, sex, nationality and education level, injury circumstances recorded as external causes of injuries, prehospital assessment, investigations and treatment in the emergency department (ED), inpatient treatment, operative procedures, complications and discharge details (online supplementary file). The Revised Trauma Score and Injury Severity Scores were calculated for each patient, using ED vital signs and Abbreviated Injury Scale, respectively. ${ }^{16}$ The electronic data collection tool was deployed on Android tablets using Open Data Kit as the open-source mHealth platform. ${ }^{19}$ Data were collected prospectively between 1 November 2014 and 30 April 2015 by trained nurses who were selected based on their routine involvement in trauma care and familiarity with medical coding systems. ${ }^{17} 20$
Khoula Hospital, a tertiary care referral hospital in Muscat, is a national trauma, burns and plastics surgery referral centre, and the country's leading neurosurgical facility. Nizwa Hospital is a secondary care hospital in the governorate of Ad-Dakhiliyah and serves as a regional trauma referral centre for neighbouring governorates. Both hospitals have highly equipped EDs, multidisciplinary trauma teams and 24/7 availability of emergency surgical services.

All patients who were admitted to the hospital with a diagnosis of injuries, (classified by International Statistical Classification of Diseases and Related Health problems 10th Revision), including those referred or transferred-in, and those who had trauma team activation (figure 1) in the ED were included in the trauma registry. Cases across both gender profiles, all age groups were included if they met the inclusion criteria. ${ }^{16}$ For the purpose of this study, only children $\leq 15$ years of age were considered for analysis, as per hospitals' definition of paediatric age group.

Descriptive statistical analysis was conducted to estimate counts, frequencies and 95\% CIs of injuries by sociodemographic factors such as age and gender, injury characteristics such as external cause, place of injury, anatomical detail, emergency and definitive care. Care at the scene was defined as care provided on route or in the field by trained or lay providers, and included interventions such as C-spine immobilisation, wound care, bleeding control, fracture immobilisation or other resuscitative measures. Univariable and multivariable Poisson regression models with robust SE were derived to test associations between the injury characteristics and in-hospital treatment, specifically surgical management. Akaike information criterion, Bayesian information criterion and $\log$ likelihood ratio tests were used to estimate best model fit in multiple logistic regression analysis. ${ }^{21}$ Statistical analyses were completed using Stata V.14 I/C package. ${ }^{22}$

\section{RESULTS}

\section{Demographics}

Children 15 years of age or under, constituted $30 \%$ of the entire sample $(n=2629)$. Around $36 \%$ were children $1-5$ years of age and $23 \%$ were under 1 year of age; two-thirds of all cases were males (table 1 ).

\section{Injury characteristics}

Transport injuries $(51 \%, 95 \%$ CI $47.5 \%$ to $54.5 \%)$ were the most common external cause of injury among all children under 15 years of age across all gender and age profiles (table 2). Exposure to inanimate mechanical forces $(20.2 \%, 95 \%$ CI $17.5 \%$ to $23.1 \%)$ and fall injuries $(11.1 \%, 95 \%$ CI $9.1 \%$ to $13.5 \%)$ followed as leading causes of injuries. However, among female children, injuries due to contact with heat and hot substances $(n=36$, $13.6 \%$ ) were the third leading cause. Almost three-quarters of all injuries occurred in the home. Around 12\% 


\section{TRAUMA TEAM ACTIVATION GUIDELINE}

\section{Assess Vital Signs and Level of Consciousness}

1. Respiratory distress / Airway compromise, and /or intubation

2. Confirmed Systolic BP $<90$ at any time

3. GCS $<8$ with mechanism attributed to trauma
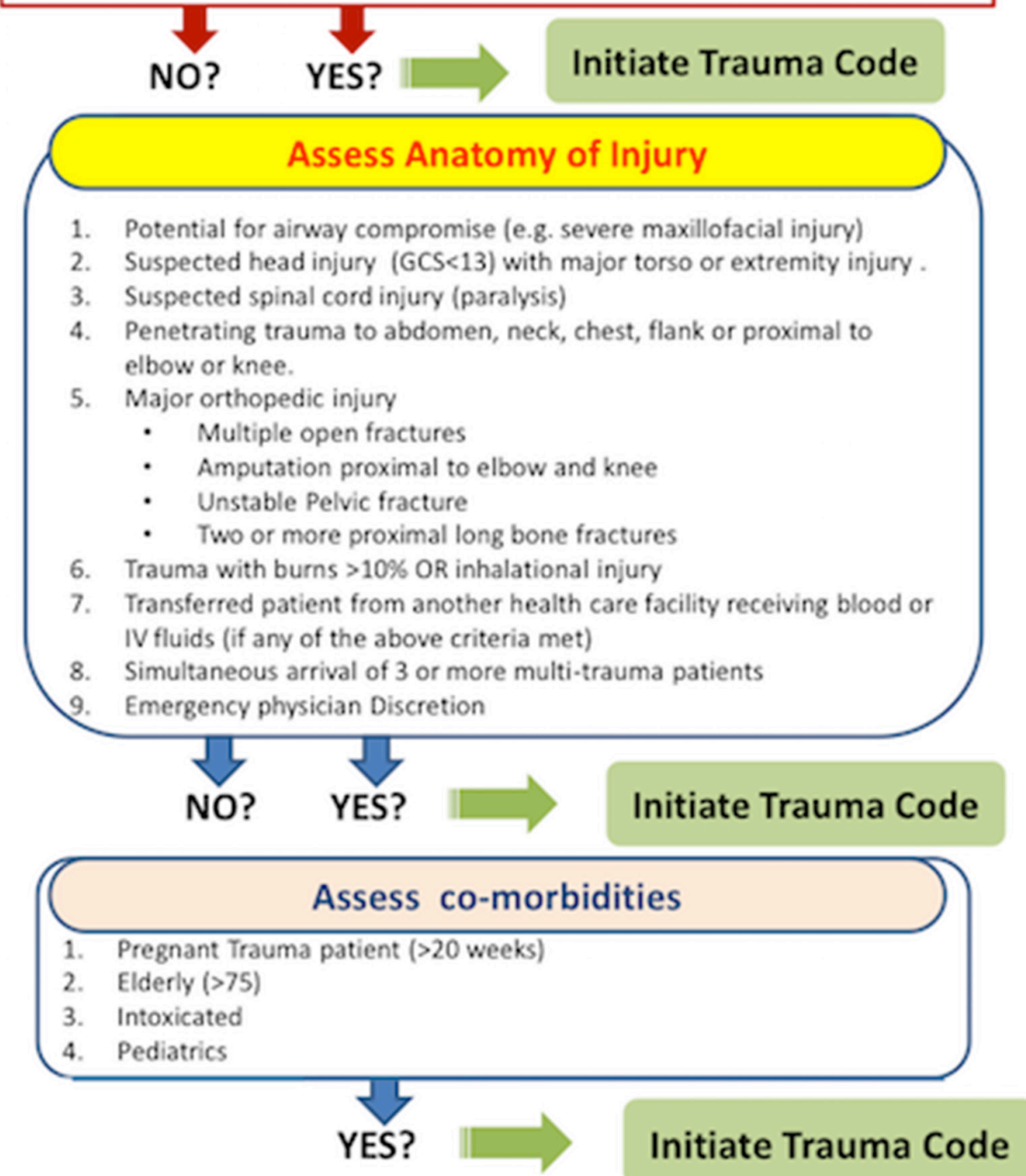

Figure 1 Trauma team activation guideline for Khoula and Nizwa Hospitals. GCS: Glasgow Coma Scale; BP: Systolic Blood Pressure measured in $\mathrm{mmHg}$

of all injuries occurred on streets, roads or highways. Only $5 \%$ of all injuries occurred on school premises or public administrative areas. Analysis by age revealed that transport injuries were the most common cause of injury for children across all age groups. Males suffered more injuries than females across all external causes of injury. Injuries by contact with heat and hot substances $(22.9 \%)$ were second most common injury cause for children $<1$ years of age, across both genders. Burn injuries were also the third leading cause of injury admissions for children $1-5$ years of age (online supplementary file 2 ).
Head injuries $(\mathrm{n}=344)$ were the most common anatomical injury among all children brought into the hospital. Most head injuries were associated with falls, followed by transport injuries. The second most common were injuries to the upper extremities, involving hands and wrists. These were seen in children who were exposed to inanimate mechanical forces such as those struck by a falling object; caught or crushed between objects, contact with non-powered tools, sharp objects or household machinery (online supplementary file 3 ). 
Table 1 Age and sex distribution of children under 15 years included in trauma registry

\begin{tabular}{lll}
\hline $\begin{array}{l}\text { Sociodemographic } \\
\text { characteristics }\end{array}$ & Total (N) & Frequency (\%) \\
\hline $\begin{array}{l}\text { Overall } \\
\text { Age }\end{array}$ & 795 & \\
$\quad<1$ year & 183 & 23 \\
\hline 1-5years & 290 & 36.5 \\
\hline 5-9years & 149 & 18.7 \\
\hline 10-15years & 173 & 21.7 \\
\hline $\begin{array}{l}\text { Gender } \\
\text { Male }\end{array}$ & \\
\hline Female & 531 & 66.8 \\
\hline & 264 & 33.2 \\
\hline
\end{tabular}

Care of injured children

Only $20.2 \% \quad(n=147)$ of all children received care at the scene of injury (table 3 ). Of the 147 children who received on-scene care, trained prehospital personnel cared for only 3.4\%; family/relatives (56.5\%) most commonly provided initial care or first aid. Most patients $(\mathrm{n}=495,68.1 \%)$ were transported to hospital by private car; only 23\% of children were transported to the hospital via EMS. About a quarter of patients were transferred or referred from another facility.

Only $8.3 \%$ reached the hospital from the scene of injury within $30 \mathrm{~min}$ of the injury, while it took more than 6 hours for 124 children (15.6\%) to be transported to the hospital. Around $39.5 \%$ of RTI patients were transported to the hospital within 1 hour of the crash, while most cases of fall injuries (54.1\%) reached the hospital within 2 hours of injury.

On arrival to the hospital, three patients $(0.4 \%)$ were pronounced dead on initial assessment. Most patients $(\mathrm{n}=732,92.1 \%)$ had minor injuries; around $75.1 \%$ patients were deemed stable enough to wait 30-60 min to receive ED treatment (ED triage code 3 ). Only $0.5 \%$ of patients had severe injuries and had been in a road traffic crash or exposed to smoke, fire or flames.

\section{Characteristics of children requiring surgery}

More than $40 \%(\mathrm{n}=303)$ of the admitted patients required surgery (table 4$)$.

Table 2 Injury characteristics among children as reported in the trauma registry

\begin{tabular}{|c|c|c|}
\hline Injury characteristics & $n(n=795)$ & Proportion $(95 \% \mathrm{Cl})$ \\
\hline \multicolumn{3}{|l|}{ External cause } \\
\hline Falls & 88 & $11.1(9.1$ to 13.5$)$ \\
\hline Transport injuries & 405 & $51.1(47.5$ to 54.5$)$ \\
\hline Exposure to inanimate mechanical forces & 160 & 20.1 (17.5 to 23.1$)$ \\
\hline Bites/animate mechanical forces & 9 & $1.1(0.6$ to 2.2$)$ \\
\hline Drowning and submersion & 3 & $0.4(0.1$ to 1.2$)$ \\
\hline Accidental suffocation and strangulation & 4 & $0.5(0.2$ to 1.3$)$ \\
\hline Exposure to smoke, fire and flames & 17 & $2.1(1.3$ to 3.4$)$ \\
\hline Contact with heat and hot substances & 73 & $9.2(7.4$ to 11.4$)$ \\
\hline Contact with venomous animals/plants & 3 & $0.4(0.1$ to 1.2$)$ \\
\hline Accidental poisoning/noxious substances & 12 & 1.5 (0.9 to 2.6$)$ \\
\hline Intentional self-harm & 1 & 0.1 (0.0 to 0.9$)$ \\
\hline Assault & 11 & $1.4(0.8$ to 2.5$)$ \\
\hline Others & 8 & $1.0(0.5$ to 2.0$)$ \\
\hline \multicolumn{3}{|l|}{ Place of injury } \\
\hline Non-institutional (private) residence & 586 & 73.8 (70.6 to 76.7$)$ \\
\hline Institutional (non-private) residence & 7 & $0.9(0.4$ to 1.8$)$ \\
\hline School, institution, public administrative area & 39 & 5.0 (3.7 to 6.7$)$ \\
\hline Sports and athletics area & 23 & $3.0(1.9$ to 4.4$)$ \\
\hline Street, highway and other paved roadways & 98 & 12.4 (10.3 to 14.9$)$ \\
\hline Trade and service area & 7 & $0.9(0.5$ to 1.9$)$ \\
\hline Industrial and construction area & 0 & 0 \\
\hline Farm & 5 & 0.7 (0.3 to 1.5$)$ \\
\hline Other places & 18 & $2.3(1.4$ to 3.4$)$ \\
\hline Unspecified place or not applicable & 11 & $1.4(0.8$ to 2.5$)$ \\
\hline
\end{tabular}




\begin{tabular}{lrc}
\hline \multicolumn{2}{l}{ Table 3 Care of injured children in Oman } \\
\hline \multicolumn{2}{l}{ Total } & Frequency (\%) \\
\hline $\begin{array}{l}\text { Care at scene } \\
\text { Yes }\end{array}$ & 147 & 20.2 \\
\hline No & 295 & 40.6 \\
Care providert & & \\
$\quad$ EMT & 5 & 3.4 \\
Bystander & 3 & 2 \\
\hline Relative & 83 & 56.5 \\
\hline Friend & 4 & 2.7 \\
Others & 56 & 38.1 \\
\hline
\end{tabular}

\begin{tabular}{|c|c|c|}
\hline & Total & Frequency (\%) \\
\hline $30 \min (3)$ & 566 & 75.1 \\
\hline $90 \min (4)$ & 158 & 20.9 \\
\hline $120 \min (5)$ & 3 & 0.4 \\
\hline \multicolumn{3}{|l|}{ Injury Severity Score } \\
\hline Minor $(\leq 9)$ & 732 & 92.1 \\
\hline Moderate (10-15) & 35 & 4.4 \\
\hline Moderate/severe (16-25) & 24 & 3 \\
\hline Severe/critical (>25) & 7 & 0.5 \\
\hline \multicolumn{3}{|l|}{ Received surgery } \\
\hline Yes & 303 & 40.9 \\
\hline No & 437 & 58.9 \\
\hline \multicolumn{3}{|l|}{ Surgical procedures } \\
\hline Khoula Hospital & 231 & 54.4 \\
\hline Nizwa Hospital & 72 & 22.8 \\
\hline
\end{tabular}

Care provided in prehospital

phaseł

\begin{tabular}{|c|c|c|}
\hline C-spine immobilisation & 15 & 8.8 \\
\hline Fracture immobilisation & 23 & 13.4 \\
\hline Control of bleeding & 23 & 13.4 \\
\hline Wound care & 82 & 47.9 \\
\hline Intravenous fluids & 16 & 9.4 \\
\hline Intubation & 0 & 0 \\
\hline Needle decompression & 0 & 0 \\
\hline CPR & 0 & 0 \\
\hline Others & 58 & 33.9 \\
\hline \multicolumn{3}{|l|}{ Mode of transport§ } \\
\hline Hospital ambulance & 112 & 15.4 \\
\hline EMS & 15 & 2.1 \\
\hline Walk-in, wheelchair & 98 & 13.5 \\
\hline Private car & 495 & 68.1 \\
\hline Others & 7 & 0.9 \\
\hline
\end{tabular}

Transport time to hospital from

time of injury§

\begin{tabular}{|lrc|}
\hline 0 to 30 min & 60 & 8.3 \\
\hline 30 min to 1 hour & 108 & 14.9 \\
\hline 1 to 2 hours & 108 & 14.9 \\
\hline >2 to 6 hours & 124 & 17.1 \\
\hline 6 to 24 hours & 73 & 10.1 \\
\hline >24 hours & 51 & 7 \\
\hline Unknown & 17 & 2.3 \\
\hline Transferred from another facility & 182 & 25.2 \\
\hline Hospital transfer & & \\
\hline Transferred from another facility & 344 & 43.3 \\
\hline Primary admission & 450 & 56.7 \\
\hline Hospital & & \\
\hline Khoula Hospital & 429 & 53.9 \\
\hline Nizwa Hospital & 366 & 46 \\
\hline ED triage code & & \\
\hline Immediate (1) & 10 & 1.3 \\
\hline 10min (2) & 17 & 2.2 \\
\hline & & \multicolumn{1}{c}{ Continued } \\
\hline
\end{tabular}

*Missing and unknown=353 (44.4\%).

$\dagger \mathrm{n}=147$ children who received care at scene.

$\ddagger \mathrm{n}=147$ some children received multiple care.

$\S$ Missing=68 (8.5\%).

ED: Emergency Department; EMS: Emergency Medical Service; EMT: Emergency Medical Technician; CPR: Cardio-pulmonary resuscitation

In the adjusted Poisson regression analysis, children 1-5 years of age were 1.9 (95\% CI 1.01 to 3.6) times at increased risk of undergoing surgery than children 10 years and above. Patients who were either directly admitted to or were transferred from other health facility to a regional referral centre were at $60 \%$ reduced risk of undergoing operation than those who were treated at a national referral centre. Additionally, when compared with patients who suffered injuries to the upper or lower extremities, patients with head, face and neck injuries (RR 8.8, 95\% CI 4.9 to 15.3), abdomen, back and pelvis injuries (RR 4.01, 95\% CI 1.5 to 10.9) and external injuries (RR 5.8, 95\% CI 1.1 to 29.9) had increased risk of surgical treatment. Patients with multiple injuries had almost five times increased risk of an operation than those with injuries to the extremities. The difference in the mean length of hospital stay was not significant for patients who underwent an operative procedure versus those who did not $(\mathrm{p}=0.514)$.

\section{DISCUSSION}

This study highlights the high burden of paediatric injuries in Oman; $>30 \%$ of all injury admissions of the two trauma centres in Oman comprised children under 15 years of age. A similar study from a primary health centre reported $41 \%$ of all injury-related visits were among children $\leq 12$ years. ${ }^{23}$ These injuries cover approximately $46 \%$ of the total DALY lost among children younger than 15 years of age in Oman. ${ }^{23}$ Taken together, these statistics 
Open access

Table 4 Multivariable Poisson regression analysis of injuries requiring surgical treatment

\begin{tabular}{|c|c|c|c|c|}
\hline \multirow[b]{2}{*}{ Characteristics } & \multicolumn{2}{|c|}{ Unadjusted } & \multicolumn{2}{|l|}{ Adjusted $^{*}$} \\
\hline & $\mathbf{R R}$ & $95 \% \mathrm{Cl}$ & $\mathbf{R R}$ & $95 \% \mathrm{Cl}$ \\
\hline \multicolumn{5}{|l|}{ Age $(n=741)$} \\
\hline 10 years and more & Reference & & Reference & \\
\hline$<1$ year & 1.9 & 1.6 to 2.3 & 1.1 & 0.3 to 1.9 \\
\hline $1-5$ years & 2.3 & 1.1 to 4.9 & 1.9 & 1.0 to 3.6 \\
\hline $6-9$ years & 1.2 & 0.9 to 1.6 & 1.3 & 0.2 to 1.7 \\
\hline \multicolumn{5}{|l|}{ Gender $(n=741)$} \\
\hline Male & Reference & & Reference & \\
\hline Female & 0.9 & 0.5 to 1.5 & 0.7 & 0.5 to 1.1 \\
\hline \multicolumn{5}{|l|}{ External cause $(n=740)$} \\
\hline Falls & Reference & & Reference & \\
\hline Transport injuries & 1.3 & 0.7 to 2.4 & 0.6 & 0.3 to 1.1 \\
\hline Exposure to inanimate mechanical forces & 0.5 & 0.4 to 0.9 & 0.5 & 0.2 to 0.9 \\
\hline $\begin{array}{l}\text { Exposure to smoke, fire, flames, heat/hot } \\
\text { substances }\end{array}$ & 1.3 & 1.1 to 1.6 & 1.5 & 0.3 to 7.5 \\
\hline Others* & 0.9 & 0.6 to 1.2 & 0.6 & 0.3 to 1.5 \\
\hline \multicolumn{5}{|l|}{ Mode of transfer $(n=680)$} \\
\hline Private car & Reference & & Reference & \\
\hline Hospital ambulance & 0.9 & 0.6 to 1.6 & 0.64 & 0.28 to 1.46 \\
\hline Royal Omani Police (ROP) ambulance & 0.4 & 0.2 to 1.7 & 0.27 & 0.07 to 1.05 \\
\hline Walk-in, wheelchair & 0.5 & 0.3 to 1.2 & 0.76 & 0.45 to 1.25 \\
\hline Others & 0.9 & 0.4 to 1.8 & 0.73 & 0.52 to 4.06 \\
\hline \multicolumn{5}{|l|}{ Hospital admission type $(n=740)$} \\
\hline Primary admission & Reference & - & Reference & - \\
\hline Transferred & 1.2 & 0.6 to 2.1 & 1.4 & 0.8 to 2.6 \\
\hline \multicolumn{5}{|l|}{ Hospital } \\
\hline National referral centre (Khoula) & Reference & & Reference & \\
\hline Regional referral centre (Nizwa) & 1.1 & 0.6 to 2.1 & 0.4 & 0.2 to 0.8 \\
\hline \multicolumn{5}{|l|}{ Emergency Room triage code $(n=700)$} \\
\hline Immediate & Reference & & Reference & \\
\hline $10 \mathrm{~min}$ & 2.8 & 0.5 to 15.5 & 0.3 & 0.04 to 3.2 \\
\hline $30 \mathrm{~min}$ & 3.3 & 0.6 to 19.3 & 0.4 & 0.1 to 5.1 \\
\hline $90 \mathrm{~min}$ & 1.8 & 0.3 to 9.9 & 0.4 & 0.1 to 2.1 \\
\hline $240 \mathrm{~min}^{*}$ & 2.7 & 0.4 to 17.3 & - & - \\
\hline \multicolumn{5}{|l|}{ Body part $(n=721)$} \\
\hline Extremities & Reference & & Reference & \\
\hline Head, face and neck & 6.2 & 3.4 to 11.5 & 8.8 & 4.9 to 15.3 \\
\hline Thorax & 3.5 & 2.2 to 5.7 & 0.7 & 0.1 to 3.3 \\
\hline Abdomen, back and pelvis & 3.7 & 2.7 to 5.2 & 4.01 & 1.5 to 10.1 \\
\hline Multiple injuries* & 2.7 & 1.4 to 5.2 & 4.9 & 1.5 to 16.3 \\
\hline External $^{\star}$ & 4.6 & 3.4 to 6.2 & 5.8 & 1.1 to 29.9 \\
\hline Others & 4.4 & 3.4 to 5.8 & 3.3 & 0.6 to 16.6 \\
\hline \multicolumn{5}{|l|}{ Injury Severity Score $(n=741)$} \\
\hline$>25$ & Reference & & Reference & \\
\hline$<10$ & 2.4 & 0.4 to 12.9 & 0.3 & 0.03 to 2.3 \\
\hline
\end{tabular}


Table 4 Continued

\begin{tabular}{|c|c|c|c|c|}
\hline \multirow[b]{2}{*}{ Characteristics } & \multicolumn{2}{|c|}{ Unadjusted } & \multicolumn{2}{|c|}{ Adjusted* } \\
\hline & RR & $95 \% \mathrm{Cl}$ & RR & $95 \% \mathrm{Cl}$ \\
\hline $10-15$ & 14.4 & 1.4 to 148.4 & 4.2 & 0.4 to 42.5 \\
\hline $15-25$ & 1.9 & 0.4 to 11.5 & 0.5 & 0.1 to 4.6 \\
\hline Revised Trauma Score $(n=297)$ & 1.2 & 0.5 to 2.7 & 2.9 & 0.9 to 9.5 \\
\hline
\end{tabular}

*Bites or exposure to animate mechanical forces, drowning and submersion, accidental suffocation and strangulation, contact with venomous animals and plants, accidental poisoning and exposure to noxious substance, intentional self-harm, assault.

highlight a remarkably high burden of injuries among young children and early adolescent population. This burden is at par with some HICs such as the USA, despite differences in social and cultural environments. ${ }^{1}$

Children under 5 were more likely to present with injuries than their older counterparts. Potential reasons could include the exploratory and curious nature of younger children, which when coupled with the lack of dexterity and coordination puts them at a higher risk of sustaining injuries. ${ }^{24}$ In some settings, heavy reliance on child care predisposes to inadequate direct parental attention, thereby putting children at risk of injuries. ${ }^{25}$ This study also found that male children were more prone to all causes of injuries, except for burn injuries where females had a proportionately higher burden. ${ }^{26}$ Similar findings have been noted previously, where young girls and women involved in the kitchen for daily cooking chores, had higher incidence of burn injuries. ${ }^{27}$

Large burden of falls, home injuries and burns demonstrate the need for age-targeted interventions. Engagement of primary caregivers in injury control programmes and 'child-safe homes' are vital in ensuring a safe environment for toddlers and young children. ${ }^{28} 29$ This includes infrastructure modifications, which coupled with parental supervision, may help reduce household injuries. ${ }^{30}$ That unintentional injuries are the predominant cause among children $\leq 15$ years in Oman is similar to previous findings from the region. ${ }^{31}{ }^{32}$ Urbanisation and increased motorisation in GCC countries have made RTIs a major concern, even for children and adolescents. $^{23} 3334$ Some researchers have documented risky behaviour among boys as young as 14 years, such as driving without a licence, performing stunts and lack of understanding of traffic rules, that increases the likelihood of traffic crashes and injuries. ${ }^{34} 35$ Programmes and policies, such as graduated drivers' licence, are needed to control traffic-related injury events in this population. ${ }^{35}$

Even though childhood injuries are a frequent cause of injury admissions, the most cases in this study presented with minor injuries and were transported to the hospital by private cars after receiving initial care from relatives. A sizeable proportion of the patients were transferred from other hospitals for further assessment or treatment; this subgroup also had statistically non-significant higher odds of surgical treatment. This illustrates that despite having a good distribution of primary health centres and smaller hospitals that provide initial assessment and stabilisation, lack of definitive treatment and major surgical facilities is the main reason for a high number of transfers and referrals, especially for paediatric population. ${ }^{1634}$

Among patients who required surgical procedures, the number of surgeries performed at Khoula Hospital was significantly higher than those performed at Nizwa Hospital. This is probably due to it being the national trauma and burns referral centre, making it more capable to provide definitive care to complex paediatric trauma patients. As Nizwa Hospital is geographically more central, closer to major highways and is the only referral hospital in the region, they usually receive more seriously injured cases especially from RTIs.

Since most patients in the trauma registry had minor injuries, ED triage code did not have any association with the need for surgical treatment. However, injuries to the head, face and neck had higher odds of being surgically treated than injury to any other body part. Injuries to the head and neck region, irrespective of their severity, pose risks of concussions, haematomas and skull fractures requiring close observation, additional radiological monitoring and neurosurgical procedures. ${ }^{36}$ Facial injuries may require expert opinion from plastics and reconstructive surgeons. Although our study does not cover long-term functional outcomes, studies have suggested increased risks of psychosocial and cognitive problems among children with minor head injuries, thus calling for efforts to prevent traumatic brain injuries. ${ }^{37}$ The data show that children who were exposed to fire, flame or smoke also had a higher likelihood of receiving surgery including surgical debridement and subsequent skin grafting. Notwithstanding that most of patients in this category had less than $10 \%$ body surface area involved, burn injuries are often associated with the high probability of long-term consequences in the paediatric population. ${ }^{38}$ The occurrence of transport injuries and head injuries also put children in need of surgical management and potential long-term disabilities ${ }^{36}$. This finding has also been highlighted in another paper focusing on Omani adolescents. ${ }^{33}$

This study is based on the data collected during the pilot phase of trauma registry implementation. Since follow-up period of patients in this trauma registry is limited to hospital discharge, we do not have information on short-term or long-term consequences of head injuries, postdischarge complications and school attendance or performance of children after injuries. 


\section{CONCLUSION}

Hospital-based trauma registry data demonstrate a high burden of injuries among children in Oman. The high incidence of falls, home injuries and burns illustrate the need for age-targeted interventions, programmes and policies changes to reduce injury events in this population.

Contributors AM conceptualised and designed the trauma registry as well as led the analysis and writing of the article. PA analysed the data and developed subsequent drafts of the manuscript. All authors contributed to writing of the article and provided technical feedback during preparation of the article.

Funding This work was funded by The Research Council of Oman through grant \# TRC/SRG/RS/13/003.

Disclaimer The content is solely the responsibility of the authors and does not necessarily represent the official view of the Research Council.

Competing interests None declared.

Patient consent Not required.

Ethics approval Ethical approval for the pilot implementation of the registry was obtained from the Johns Hopkins School of Public Health in USA and Oman's Ministry of Health.

Provenance and peer review Not commissioned; externally peer reviewed. Open access This is an open access article distributed in accordance with the Creative Commons Attribution Non Commercial (CC BY-NC 4.0) license, which permits others to distribute, remix, adapt, build upon this work non-commercially, and license their derivative works on different terms, provided the original work is properly cited, appropriate credit is given, any changes made indicated, and the use is non-commercial. See: http://creativecommons.org/licenses/by-nc/4.0/.

\section{REFERENCES}

1. Institute for Health Metrics and Evaluation. Global Burden of disease results tool. 2016.

2. World Health Organization. Injuries and violence: the facts 2014 . 2014.

3. Peden M. World report on child injury prevention: World Health Organization, 2008.

4. World Health organization Global Health Estimates 2015. World Health Organization Geneva 2016.

5. Injuries WHO, Department VP. The injury chart book: a graphical overview of the global burden of injuries: World Health Organization, 2002.

6. Norton R, Hyder AA, Bishai D, et al. Chapter 39: Unintentional Injuries. In: Disease control priorities in developing countries. , 2006:2, 737-53.

7. Boutayeb A, Boutayeb S. The burden of non communicable diseases in developing countries. Int J Equity Health 2005;4:2.

8. Ansari S, Akhdar F, Mandoorah M, et al. Causes and effects of road traffic accidents in Saudi Arabia. Public Health 2000;114:37-9.

9. Barss P, Addley K, Grivna M, et al. Occupational injury in the United Arab Emirates: epidemiology and prevention. Occup Med 2009;59:493-8.

10. Kronfol NM. Historical development of health systems in the Arab countries: a review. East Mediterr Health J 2012;18:1151-6.

11. Makhoul J, El-Barbir F. Obstacles to health in the Arab world. BMJ 2006;333:859.1.

12. Islam MM, Al Hadhrami AY. Increased motorization and road traffic accidents in Oman. J Emerging Trends in Economics and Management Sciences 2012;3:907.

13. Boutayeb A, Serghini M. Health indicators and human development in the Arab region. Int J Health Geogr 2006;5:61.
14. World Population Review, 2018. Oman Population 2018. http://worl dpopulationreview.com/countries/oman-population/ (accessed 13 Feb 2018).

15. Annual Health Report M.o.H. Department of health information and statistics. Muscat, Oman: Ministry of Health, Sultanate of Oman, 2016.

16. Mehmood A, Allen KA, Al-Maniri A, et al. Trauma care in Oman: a call for action. Surgery 2017;162:S107-16.

17. Mehmood A, Chan E, Allen K, et al. Development of an mHealth trauma registry in the Middle East using an implementation science framework. Glob Health Action 2017;10:1.

18. Bener A, Al-Salman KM, Pugh RN. Injury mortality and morbidity among children in the United Arab Emirates. Eur J Epidemiol 1998;14:175-8.

19. Gennarelli TA, Wodzin E. Abbreviated injury scale 2005: update 2008 Russ Reeder, 2008.

20. Hartung C, Lerer A, Anokwa Y, et al. Open data kit: tools to build information services for developing regions. Proceedings of the 4th ACM/IEEE international conference on information and communication technologies and development: ACM, 2010.

21. Vrieze SI. Model selection and psychological theory: a discussion of the differences between the Akaike information criterion (AIC) and the Bayesian information criterion (BIC). Psychol Methods 2012;17:228-43.

22. LPSC. Stata Statistical Software Release 9: Stata Press Publication, 2005.

23. Al-Balushi $\mathrm{H}, \mathrm{Al}-\mathrm{Kalbani} \mathrm{A}, \mathrm{Al}-\mathrm{Khw}$ aldi $\mathrm{T}$, et al. Injuries presented at a primary care setting in oman. Oman Med J 2012;27:486-90.

24. Gururaj G. Injury prevention and care: an important public health agenda for health, survival and safety of children. Indian $J$ Pediatr 2013;80:100-8.

25. Al-Lamky A. Modernization and child neglect in Oman: trends and implications. Int J World Peace 2004:43-53.

26. Alonge $\mathrm{O}$, Hyder AA. Reducing the global burden of childhood unintentional injuries. Arch Dis Child 2014;99:62-9.

27. Peck MD. Epidemiology of burns throughout the world. Part I: distribution and risk factors. Burns 2011;37:1087-100.

28. He S, Alonge O, Agrawal $\mathrm{P}$, et al. Epidemiology of burns in rural bangladesh: an update. Int J Environ Res Public Health 2017;14:381.

29. Mack KA, Liller KD, Baldwin G, et al. Preventing unintentional injuries in the home using the Health Impact Pyramid. Health Educ Behav 2015;42:115S-22.

30. Morrongiello BA, Kiriakou S. Mothers' home-safety practices for preventing six types of childhood injuries: what do they do, and why? J Pediatr Psychol 2004;29:285-97.

31. Kendrick D, Barlow J, Hampshire A, et al. Parenting interventions for the prevention of unintentional injuries in childhood. Cochrane Database Syst Rev 2007;4:CD006020.

32. Bener A, el-Rufaie OE, al-Suweidi NE. Pediatric injuries in an Arabian Gulf country. Inj Prev 1997;3:224-6.

33. Bachani AM, Taber N, Mehmood A, et al. Adolescent and young adult injuries in developing economies: a comparative analysis from Oman and Kenya. Ann Glob Health 2017;83:791-802.

34. Al-Reesi H, Ganguly SS, Al-Adawi S, et al. Economic growth, motorization, and road traffic injuries in the Sultanate of Oman, 1985-2009. Traffic Inj Prev 2013;14:322-8.

35. Belwal R, Belwal S, Al Quraini A. Road Traffic Accidents (RTAs) and road safety in Oman: an analysis of people's perception towards the causes. Advances in Transportation Studies 2015.

36. Murshid WR. Management of minor head injuries: admission criteria, radiological evaluation and treatment of complications. Acta Neurochir 1998;140:56-64.

37. Silver JM, Kramer R, Greenwald S, et al. The association between head injuries and psychiatric disorders: findings from the New Haven NIMH Epidemiologic Catchment Area Study. Brain Inj 2001;15:935-45.

38. Landolt MA, Buehlmann C, Maag T, et al. Brief report: quality of life is impaired in pediatric burn survivors with posttraumatic stress disorder. J Pediatr Psychol 2009;34:14-21. 